\title{
BENEFITS OF MODULARITY AND MODULE LEVEL TESTS
}

\author{
Patrik Kenger \\ Dalarna University and the Royal Institute of Technology, SWEDEN \\ pke@du.se
}

\begin{abstract}
Many companies implement a modular architecture to support the need to create more variants with less effort. Although the modular architecture has many benefits, the tests to detect any defects become a major challenge. However, a modular architecture with defined functional elements seems beneficial to test at module level, so called MPV (Module Property Verification). This paper presents studies from 29 companies with the purpose of showing trends in the occurrence of defects and how these can support the $M P V$.
\end{abstract}

\section{INTRODUCTION}

Any product or process defect causes losses, and these will be repeated unless a more formalized approach to the problem is taken. Today product tests to detect defects are necessary but they are a difficult phase in industry which results in both extension of lead-times and increased costs, O'Connor (2003). The difficulties are caused by lack of time and knowledge of how to plan and perform the tests in the assembly system; and how to design products which are suitable for, or at least facilitate, tests. In this paper product verification denotes the process of determining whether or not the product at a given phase in the life-cycle fulfils its properties. This definition includes the commonly used word test, but also manual inspection and quality control, and the planning, evaluation and documentation of the verification r esults. The trend of sh orter lead-times and life c ycles, Onori (2003), seems to further enhance the difficulties. Since every new variant introduced in the assembly line has its own properties, it also needs its own specific verification. The operators performing the verifications face an impossible task: verifying increasing volumes and variants with the same amount of personnel and equipment. This is the case at one company where the actual verification process has become the bottleneck. One way to handle lead-time and cost of verification is to r educe the verification itself. Although this will cut cost and time, Varma (1995) points out that it is more important to focus on product profitability and verification strategies.

However, modularity has proven to have benefits related to defects and verifications. The goal of this paper is to show the correlation between a modular 
architecture, module level verification and a potential decrease in design and assembly defects. The discussions in the paper also have a direct bearing upon the correct implementation of re-configurable or evolvable assembly systems, Onori (2003), which strongly rely upon system modularity.

\section{MODULAR ARCHITECTURES}

To keep up with increased volumes and product variants companies strive to implement a modularized product assortment. Modularization has shown to have numerous benefits, see e.g. Ulrich and Tung (1991), Erixon (1998), Stake (2000), or Baldwin and Clark (2000). In fact many Swedish companies have successfully utilized modularity to stay competitive. Among these are Scania and VBG, see Erixon (1998), ABB, VOLVO, and ITT Flygt, see Stake and Blackenfelt (1998). One studied company shows a potential increase of 6700 variants (theoretically possible variants) and a decrease of 7000 parts after two years of modular implementation, Table 1 .

Table 1: Benefits of a modular architecture

\begin{tabular}{|c|c|c|c|}
\hline $\begin{array}{l}\text { Product } \\
\text { architecture }\end{array}$ & Years & Variants & $\begin{array}{l}\text { Number of } \\
\text { different parts }\end{array}$ \\
\hline Integrated & 30 & 300 & 10000 \\
\hline Modular & 2 & 7000 & 3000 \\
\hline
\end{tabular}

The product architecture in Table 1 denotes the scheme of the functional elements of the product, Huang (1999), and how these elements are arranged into physical blocks (modules) and the blocks interaction. Huang (1999) describes a modular architecture as the architecture where the functional element is implemented by one block which has few but well defined interactions between other blocks. The integrated architecture is characterized by optimization of a certain performance. The interactions between blocks in an integrated architecture are not as defined as in the modular case, as each block embodies several functions.

However, the company described in Table 1 has a challenge to be faced before the full potential of the modular architecture may be utilized. The company plans to have a minor module storage in which final assembly selects module variants that fit the product the customer asked for. The modules and the module storage will support a potential lead-time decrease of $450 \%$. This decrease though is only possible if defect-free modules are available from storage. The challenge is to verify the increased product variants, made possible by the modular architecture, and to do it on module level. In Figure 1, the challenge is described with 4 modules $(1,2,3, j)$ with $5,3,7$, and 2 variants. If the verification is performed at product level, the 210 possible variants need 210 verifications. This number is reduced to 17 verifications if the product verifications are performed at module level. 

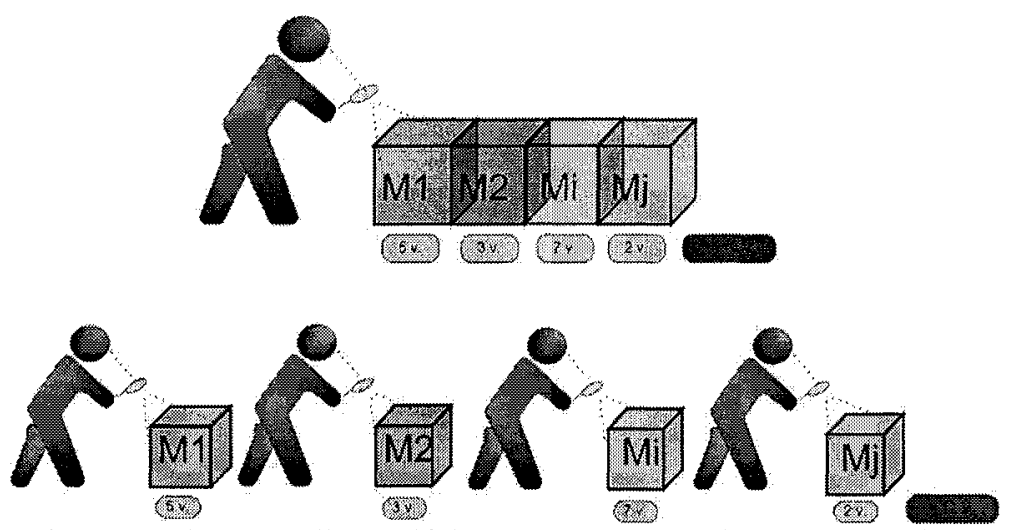

Figure 1: Theoretically, verifying products at product level requires 210 verifications to cover the whole product range, while module level requires 17 .

\subsection{Modular verification}

There are more benefits to be obtained by module level verifications then just a decrease in the number verifications. Researchers and companies studied agree that the product verifications should take place early in the value chain, discussed by Baudin (2002), Robinson et al. (1988), and Nevins and Whitney (1989). The more time spent on embodiment of the product, and the more parts manufactured and added to the product, the greater the value added. At the same time the complexity of the product increases, i.e. more parts are added which give the product more details and functions. The approach to verify the product early in the value chain is specifically beneficial in a modularized product assortment where specified functions and interfaces in each module can be verified already at the module assembly workshop, so called module property verification (MPV), Kenger et al. (2003). As discussed above, a modular architecture has few or one function in each module which in turn simplifies the verification. Benefits of MPV have been discussed by among others Baldwin and Clark (2000), Erixon (1998), Baudin (2002) and Stake (2000). As pointed out in Kenger and Onori (2003), by performing MPVs, detected defects can be repaired at module level where less parts have to be disassembled, spare parts are already available at the module assembly workshop, and no additional assembly or verification tools are necessary since they are also available in the module assembly workshop.

Even though there are several benefits by performing MPVs, there may be reasons for performing the verifications at product level, so called product property verification (PPV). PPV may be more beneficial to perform when the number of defects per product (defect rate) is relative low. Only a final check of the product is performed as a precaution to ensure the compatibility of the parts or modules building up the product. Compared with MPV, there is less number of separate verifications in PPV since one PPV might correspond to several MPV's. That is, at module level each module may need its own verification while it may be enough with a single verification on product level. All in all, it is necessary to measure the benefits of MPV compared to PPV to avoid costly rearrangements at the point of verification which in turn affects both the assembly system and the module design. 


\section{DESIGN AND ASSEMBLY DEFECTS}

A way to measure the benefits of MPV is to analyze occurred design and assembly defects. How often, the causes, and defect trend can show where it would be beneficial with MPV. Here, a defect is a fault that causes the product not to fulfill its properties, i.e. the product does not work or have the intended appearance. Defects themselves are a symptom of poor machines, designs and routines where the defect origin is claimed to always be human. Baudin (2002) and Shingo (1986) point out that verifications to detect defects are a waste of time and resources since it does not add any value to the customers' interpretation of the product. Thereby, the most profitable way to verify is not to verify at all which in turn is related to increase risks of having defect products shipped to customers. Also, the verifications themselves do not contribute to reducing the defects. Case studies, presented below, show that zero defects is an utopia, at the same time demands on verifications increases from customers, standards and governments. Therefore, verifications are necessary but should be performed with a minimum of time and resources. This means that personnel, verification equipment, documentation and preparation have to be optimized and verify the exact demanded properties.

Branan (1991) showed a relationship between defects per million parts and manual assembly efficiency. This relation was further analyzed by Barkan and Hinckley (1994). They show that longer assembly times are related to difficult assembly tasks which increase the probability that a defect may occur. Five assembly factors are also identified related to a qualitative product. (1) Assembly operations, (2) assembly quality control, (3) assembly operation complexity, (4) number of parts, and (5) part defect rate. A relationship between assembly time and the defect rate (defects per product) can also be seen in Table 2 .

Table 2: The relation between assembly time and defect rate

\begin{tabular}{ll|ll}
\hline Assembly time & Defect rate & Assembly time & Defect rate \\
$<0.5$ hour & $<0.01$ & 0,5 to 1 hour & 0.2 to 0.5 \\
$<0.5$ hour & $<0.01$ & 1 to 2 hours & 0.2 to 0.5 \\
$<0.5$ hour & $<0.01$ & 2 to 3 days & 0.2 to 0.5 \\
0,5 to 1 hour & $<0.01$ & 2 to 3 days & 0.2 to 0.5 \\
1 to 2 hours & $<0.01$ & $>2$ weeks & 0.2 to 0.5 \\
1 to 2 hours & $<0.01$ & 1 to 2 hours & 0.6 to 1 \\
5 to 10 hours & $<0.01$ & 1 to 2 hours & 0.6 to 1 \\
$<0.5$ hour & 0.01 to 0.1 & $>2$ weeks & 0.6 to 1 \\
$<0.5$ hour & 0.01 to 0.1 & 2 to 3 hours & 1.5 to 2 \\
$<0.5$ hour & 0.01 to 0.1 & 5 to 10 hours & 2.1 to 5 \\
0,5 to 1 hour & 0.01 to 0.1 & 2 to 3 days & 5.1 to 10 \\
1 to 2 hours & 0.01 to 0.1 & 1 to 2 weeks & 5.1 to 10 \\
2 to 3 hours & 0.01 to 0.1 & $>2$ weeks & 5.1 to 10 \\
3 to 5 days & 0.01 to 0.1 & $>2$ weeks & 5.1 to 10 \\
3 to 5 hours & 0.01 to 0.1 & & \\
\hline
\end{tabular}

Each assembly time in Table 2 corresponds to a certain defect rate given by a surveyed company. The trend is that longer assemblies results in more defects than 
shorter ones. The questionnaire was answered by 27 Swedish companies and 2 Norwegian companies. $82 \%$ of the responding companies claimed that their products were built up by modules or subassemblies, and $18 \%$ that the product has an integrated architecture. Of the same companies, $88,5 \%$ answered that their products is mainly assembled manually, and the other $11,5 \%$ that they are mainly assembled automatically. At one company a case study was performed and 1600 defects reported over an 8 year period were analyzed. The cost of assembly and design defects in Figure 2, 3, and 4 are designated to specific departments. This means that it is a design defect if the design department is charged for the repair of the subsequent defect. The same goes for assembly defects. Each dot in Figure 1,2 and 3 represents a customer order of a certain volume. As can be seen in Figure 2 and 3 the trend is that the defect rate decreases as the order volume increases.

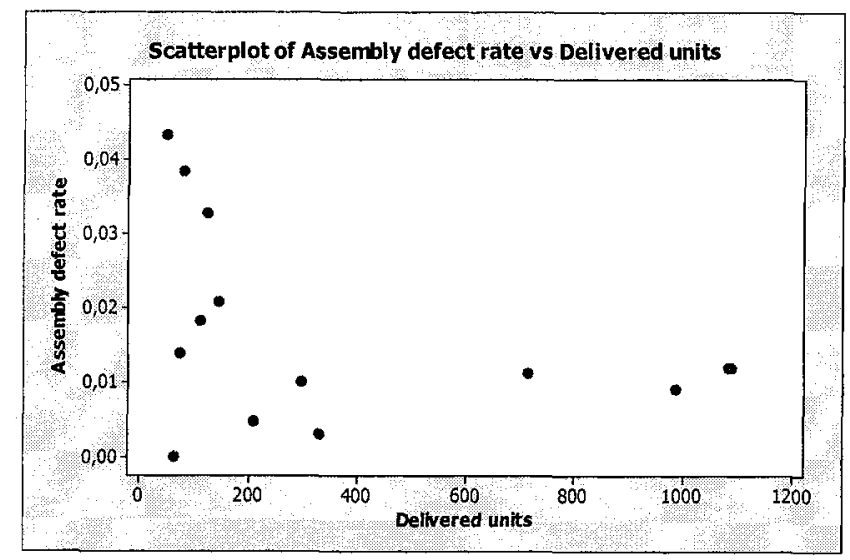

Figure 2: Assembly defect rate and delivered units.

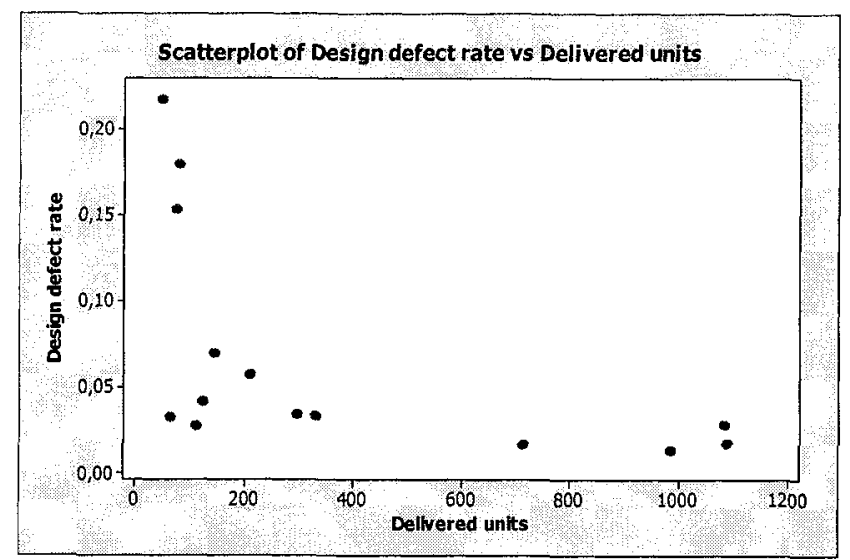

Figure 3: Design defect rate and delivered units.

The design and assembly defects were plotted against each other in order to analyze a possible correlation, Figure 4 . The sample correlation coefficient was shown to be 
0,83 which is a strong relation, Johnson (2000). This in turn implies that a design which is complex (many parts and many functions) later on also causes the assembly operators to make mistakes.

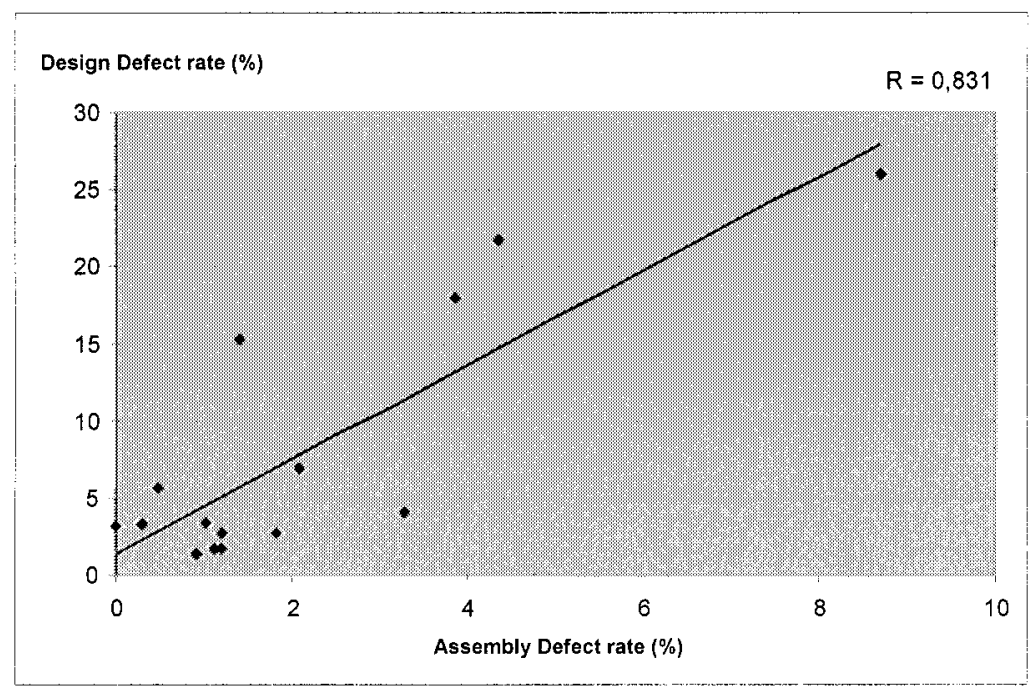

Figure 4: Least square estimate with a sample correlation coefficient $\mathrm{R}=0,83$ which indicates a strong relation between design and assembly defects.

\subsection{Difference between design and assembly defects}

Even though there is a strong relation between the design and assembly defects, there is a major difference in how they occur. Design defects can be said to occur over a period of time, somewhere during the design process between the gathering of customer needs and the detail design. The design process at the studied company often involves several designers, the design team, who together design the product. Design defects can be detected by the designers themselves, making the design team working as a net which detects defects in time, before the repair becomes much more costly. Design defects, passing the net, can be called consequential design defects, originating from having the "wrong thinking" within the team. Consequential defects denote that the "wrong thinking" which caused the defect, follows the design all the way through the design process. These consequential defects occur even if there is one designer working with the development of the product; each time the designer starts a new working day, or opens up the CADsoftware the defect is overlooked and designed "into" the product. Consequential design defects can be difficult to detect since each designed part, sub-assembly, or module may possess a design defect which is not revealed until the product is virtually assembled, simulated or, worse, manufactured and assembled as a physical product. The designer(s) guilty of the "wrong thinking" may therefore not be aware of the design defect until the product actually physically exists. However, frequency of design defects is related to the maturity of the product. Given that the design team is made up of the same members, during the period of design and delivery of the 
product the design team learns from previous "wrong thinking" and consequential design defects as well as being more and more familiar with the intended function of the product or its parts. This in turn explains the decreased defect rate at higher volumes.

Assembly defects occur more instantly compared to design defects. For example, inserting a part can be done the right or wrong way, where the actual assembly defect (wrong insertion) occurs at the same moment as the part is inserted. The assembly defect is not made by systematically having the "wrong thinking" to the same extent as design defects, but more of the presence and the experience the assembly worker possesses. Although, a systematic pattern is difficult to see in assembly defects, the assembly workers also said that they become more familiar and learn in similar ways to the designers.

After analyzing the defects at the studied company, the result was presented to design and assembly personnel, including the managers. They agreed upon the different ways design and assembly defects can occur.

\section{SUMMARY}

Verifying products is one of the areas where there is still much to be gained for some companies. It has been shown that defects occur even though preventive measures are taken. However, not only the actual verification is important but also where in the value chain it is performed, how easy it is to detect each defect as well as repairing them.

Modular architectures have numerous benefits, where several of them are related to verifications and defects. Figure 2 and 3 show that as the volume increases the defect rate decreases in design and assembly defects. It was clear from the study that the defect reduction can be explained by learning about the product and being familiar with the work. Modularization gives higher volumes from a decreased number of parts, as well as smaller assemblies, which take less time to assemble. This can have the same effect as having an integrated architecture and high volumes. However, in the modular case the order volume can be one unit and still obtain the benefits of reduced defects.

To decide whether MPV or PPV is the most economical and time efficient way to verify, statistics on defects can serve as a measure. If a relative high defect rate of a certain defect occurs, say assembly defects, then it would most probably be beneficial to perform MPVs. Similarly if a minor storage of modules will be held, to cut the lead-time, MPVs would probably be beneficial. However, if the defect rate is relative low, as well as the cost to repair defects, the PPV approach is suggested. In the MPV case, more verification stations are needed to correspond to one PPV, see Figure 1. Also more test and assembly fixtures (TAFs) are needed in the MPV case, which increases the initial cost when moving from PPV to MPV. 


\subsection{Further work}

The collected data, more than given room for here, will serve as input to develop a prototype of a module assembly line. A TAF is being built to perform MPVs for a proposed module, which shall be part of the assembly line. The prototype line should run long enough to compare numbers from the line today, the defect rate and time to repair, with the prototype line and its defect rates and time to repair. The work is also being proposed to be integrated within an Evolvable Assembly Systems project called $A^{3}$-Applied Agile Assembly, to be performed within industry under the leadership of IntRoSys SA, a Portuguese SME.

\section{REFERENCES}

1. Baldwin, C., Y., Clark, K., B ., (2000), Design Rules - The P ower of M odularity, M assachusetts: MIT Press, ISBN 0-262-02466-7

2. Barkan, P., Hinckley, M., (1994), Benefits and Limitations of Structured Methodologies in Product Design, Management of Design, Engineering, and Management perspectives, USA: Kluwer Academic Publishers, ISBN 0-7923-9509-3

3. Baudin, M., (2002), Lean Assembly - The Nuts and Bolts of Making Assembly Operations Flow, New York, USA: Productivity Press, ISBN:1-56327- 263-6

4. Branan, B., (1991), Six Sigma Quality and DFA, DFMA Insight, Vol. 2, Winter 1991

5. Erixon, G., (1998), Modular Function Deployment - A Method for Product Modularization, Doctoral Thesis, Stockholm: The Royal Institute of Technology, ISSN 1104-2141

6. Huang, C., C., (1999), Overview of Modular Product Development, Proc. Natl. Sci. Counc., Vol. 24,

7. No. 3

8. Johnson, R., A., (2000), Probability and Statistics for Engineers, $6^{\text {th }}$ Edition: Prentice-Hall, ISBN 013- 014158-5

9. Kenger, P., Onori, M., (2003), Module Property Analysis in the Assembly Process, International Precision Assembly Symposium: Bad Hofgastein, Austria

10. Kenger, P., Erixon, G., Lennartsson, S., (2003), Module Property Verification - A Conceptual Framework to Perform Product Verifications at Module Level, 14th International Conference on Engineering Design, 19-21 August, Stockholm, Sweden

11. Nevins, J., L., Whitney, D., E., (1989), Concurrent Design of Products and Processes - A Strategy for the Next Generation in Manufacturing, USA: McGraw-Hill, ISBN 0-07-0463417

12. O'Connor, P., (2003), Testing for Reliability, Quality and Reliability Engineering International

13. Onori, M., Barata, J., Lastra, J., M., Tichem, M., (2002), European Precision Assembly Roadmap 2010, Assembly-Net Report to EC, Assembly-Net (G1RT-CT-2001-05039)

14. Robinson, L., W., McClain, J., O., Thomas, L., J., (1990), the Good, the Bad and the Ugly: Quality on Assembly Line, International Journal of Production Research, Vol. 28 No. 5

15. Shigeo, S., (1986), Zero Quality Control - Source Inspection and the Poka-yoke System, Portland, USA: Productivity Inc., ISBN 0-915299-07-0

16. Stake, R. B., (2000), On Conceptual Development of Modular Products - Development of Supporting Tools for the Modularization Process, Doctoral Thesis, Stockholm: The Royal Institute of Technology, ISSN 1650-1888

17. Stake, R., B., Blackenfelt, M., (1998), Modularity in Use - Experiences from five companies, $4^{\text {th }}$

WDK Workshop on Product Structuring: Delft University of Technology, The Netherlands

18. Ulrich K, and Tung K, (1991) "Fundamentals of Product Modularity", DE-Vol. 39, Issues in Design Manufacture/Integration, ASME

19. Varma, P., (1995), Optimizing Product Profitability - The Test Way, International Test Conference 